\title{
ESTUDO DOS REGIMES HIDROLÓGICOS DE SETE RIOS SELECIONADOS NOS CINCO CONTINENTES DO MUNDO.
}

\author{
Juliana Alencar Firmo de Araújo' \\ Raquel Jucá de Moraes Sales ${ }^{2}$ \\ José Nilson Beserra Campos ${ }^{3}$
}

Resumo - Este artigo teve como objetivo a comparação de regimes hidrológicos de sete rios selecionados em cinco continentes do mundo. Foram selecionados rios dos seguintes países: Sudão, Estados Unidos, Brasil, China, Alemanha, Austrália e Rússia. Os dados foram obtidos através do site da Organização das Nações Unidas para a Educação, Ciência e Cultura (UNESCO). Foram avaliadas as seguintes características hidrológicas: sazonalidade, autocorrelação, coeficientes de variação e vazões máximas. Primeiramente foi feito o cálculo de autocorrelação das vazões e depois foi aplicado o teste qui-quadrado para avaliar a aderência das amostras. Foi calculada a série de vazões máximas de cada local, e realizadas análises estatísticas relacionando vazão com probabilidade nos períodos de retorno de 10, 50, 100, 1000 e 10000 anos. Os resultados demonstraram que o país que apresentou o maior coeficiente de variação foi do rio na Austrália, e o rio na China apresentou o menor coeficiente de variação, o que representa um conjunto de dados mais homogêneo. A distribuição normal, a distribuição gama e a distribuição log-normal foi a que melhor ajustou os dados do rio São Francisco (Brasil), do rio Murray Kiewa (Austrália), e do rio Danube (Alemanha) assim como do rio Okhotskiy Perevoz (Rússia), respectivamente.

Palavras-Chave: Descargas fluviais. Sazonalidade. Função distribuição de descargas anual.

1) Doutoranda em Recursos Hídricos pela Universidade Federal do Ceará e bolsista do CAPES. Campos do Pici, CEP- 60445-760. Bloco 713. Fortaleza - Ceará. e-mail: judiarauio@yahoo.com.br;

2) Doutoranda em Recursos Hídricos pela Universidade Federal do Ceará e bolsista do CNPq. Campos do Pici, CEP- 60445-760. Bloco 713. Fortaleza - Ceará. e-mail: raqueljuca@gmail.com;

3) Professor do Departamento de Engenharia Hidráulica e Ambiental. Campus do Pici, Centro de Tecnologia, Bloco 713, Fortaleza Ceará, Brasil, CEP 60445-760, e-mail: nilson@ufc.br. 


\section{INTRODUÇÃO}

Para uma gestão e planejamento racional dos recursos hídricos se faz necessário o conhecimento de dados hidroclimatológicos. Em estudos hidrológicos utilizam-se muito os cálculos estatísticos com objetivo de estimar as probabilidades de acontecimento de um determinado evento extremo ou o tempo de recorrência de um evento. Para estudos de disponibilidade e regularização de vazões é fundamental o conhecimento do regime hidrológico dos rios.

Este trabalho teve como objetivo principal estudar o regime hidrológico de sete rios do mundo para avaliar suas diferenças. Foram estudadas as seguintes características: autocorrelação das vazões anuais, sazonalidade intraannual, função de densidade de probabilidade de melhor ajuste às séries históricas e estatísticas de vazões máximas.

\section{DADOS E MÉTODOS}

Os dados de vazões foram obtidos por meio de pesquisa na internet no site da UNESCO: onde é possível obter dados de vazão de vários locais do mundo. Neste trabalho foram escolhidos rios de sete países: Sudão, Estados Unidos, Brasil, China, Alemanha, Austrália e Rússia. Os dados gerais de cada estação escolhida está descrita na Tabela 1.

Tabela 1 - Descrição das estações escolhidas.

\begin{tabular}{|c|c|c|c|c|c|c|c|c|c|}
\hline CONTINENTE & PAís & RIO & ESTAÇÃo & $\begin{array}{c}\text { ÁREA } \\
\left(\mathbf{k m}^{2}\right)\end{array}$ & $\begin{array}{c}\text { LATITUDE } \\
\left(^{(}\right)\end{array}$ & $\begin{array}{c}\text { LONGITUDE } \\
\left(^{\circ}\right)\end{array}$ & $\begin{array}{c}\text { ANO } \\
\text { INICIAL }\end{array}$ & $\begin{array}{c}\text { ANO } \\
\text { FINAL }\end{array}$ & $\begin{array}{c}\text { TOTAL } \\
\text { DE } \\
\text { ANOS }\end{array}$ \\
\hline África & Sudão & $\begin{array}{c}\text { Bahr el } \\
\text { Jabel }\end{array}$ & Mongalia & 450000 & 5.2 & 31.77 & 1912 & 1982 & 71 \\
\hline $\begin{array}{c}\text { América do } \\
\text { Norte }\end{array}$ & $\begin{array}{c}\text { Estados } \\
\text { Unidos }\end{array}$ & $\begin{array}{c}\text { Apalachicol } \\
\text { a }\end{array}$ & $\begin{array}{c}\text { Chattahooche } \\
\text { e }\end{array}$ & 44548 & 30.7 & -84.87 & 1929 & 1984 & 56 \\
\hline $\begin{array}{c}\text { América do } \\
\text { Sul }\end{array}$ & Brasil & $\begin{array}{c}\text { São } \\
\text { Francisco }\end{array}$ & Juazeiro & 510800 & -9.81 & -40.5 & 1929 & 1979 & 51 \\
\hline Ásia & China & Chanjiang & Yichang & 1005500 & 30.4 & 111.14 & 1882 & 1981 & 100 \\
\hline Europa & Alemanha & Danube & Hofkirchen & 47495 & 48.67 & 13.12 & 1901 & 1986 & 86 \\
\hline Oceania & Austrália & $\begin{array}{c}\text { Murray } \\
\text { Kiewa }\end{array}$ & Kiewa & 1165 & -36.27 & 147.03 & 1886 & 1965 & 80 \\
\hline $\begin{array}{c}\text { Pós- } \\
\text { Soviéticos }\end{array}$ & Rússia & Aldan & $\begin{array}{c}\text { Okhotskiy } \\
\text { Perevoz }\end{array}$ & 514000 & 61.87 & 135.5 & 1936 & 1990 & 55 \\
\hline
\end{tabular}

Fonte: UNESCO, 1977 \& UNESCO, 1978. 
Foram estudadas as seguintes características para descrever a potencialidade do rio prover suprimento de água com segurança hidrológica: o regime médio de vazões, a autocorrelação dos deflúvios anuais, a sazonalidade intraannual, as vazões específicas de cheias de vários períodos de retorno e a função de densidade de probabilidade de melhor aderência. A seguir descrevem-se as metodologias usadas para descrever cada uma dessas características.

\subsection{Regime de vazões médias}

O regime das vazões médias é normalmente determinado por duas estatísticas: o defúvio médio anual e o coeficiente de variação. O coeficiente de variação é uma relação entre o desvio-padrão e a média, ou seja, mede a variabilidade dos valores em torno da média.

Considerando-se que foram avaliadas bacias hidrográficas de grande variação em área, apresentou-se também a vazão média específica, que é para retirar o valor de escala.

\subsection{Autocorrelação das vazões anuais}

A autocorrelação reflete a capacidade da bacia hidrográfica manter suas águas estocadas de um ano para outro. Quanto maior for o valor deste parâmetro, maior a probabilidade de sequência de anos secos ou úmidos. Em solos cristalinos praticamente não há autocorrelação, pois há dificuldade em estocar água por ser altamente permeável.

\subsection{Sazonalidade intraanual}

Um dos aspectos mais importantes do clima e da hidrologia de uma região é a época de ocorrência das chuvas. Existem regiões com grande variabilidade sazonal da chuva, com estações do ano muito secas ou muito úmidas. A variabilidade sazonal da chuva é representada por gráficos com a chuva média mensal.

\subsection{Vazões específicas de cheias}


Selecionando apenas as vazões máximas de cada ano em um determinado local, é obtida a série de vazões máximas deste local e é possível realizar análises estatísticas relacionando vazão com probabilidade.

\subsection{Função de probabilidade de melhor aderência}

As distribuições utilizadas neste trabalho foram a Normal, Log-Normal e Gama.

O valor crítico do $\chi^{2}$ é obtido da tabela estatística da distribuição inversa do quiquadrado e é função do número de graus de liberdade $(\eta)$ e do nível de significância do teste. Para todos os casos foi admitido um nível de significância de $90 \%$. O valor do grau de liberdade é:

$$
\eta=k-m-1
$$

Onde $\mathrm{k}$ é o intervalo considerado e $\mathrm{m}$ o número de parâmetros, que no caso é igual a dois (média e desvio padrão). Logo, a equação acima pode ser resumida:

$$
\eta=k-3
$$

\section{ANÁLISE DOS RESULTADOS}

\subsection{Regime de vazões médias}

A Tabela 2 apresenta os dados após o levantamento das características hidrológicas das vazões dos sete países.

\begin{tabular}{|c|c|c|c|c|c|c|c|}
\hline & SUDÃO & $\begin{array}{l}\text { ESTADOS } \\
\text { UNIDOS }\end{array}$ & BRASIL & CHINA & $\begin{array}{c}\text { ALEMANH } \\
\text { A }\end{array}$ & $\begin{array}{c}\text { AUSTRÁLI } \\
\text { A }\end{array}$ & RÚSSIA \\
\hline Parâmetro & $\begin{array}{c}\text { Rio Bahr el } \\
\text { Jabel }\end{array}$ & $\begin{array}{c}\text { Rio } \\
\text { Apalachicola }\end{array}$ & $\begin{array}{l}\text { Rio São } \\
\text { Francisco }\end{array}$ & $\begin{array}{c}\text { Rio } \\
\text { Chanjiang }\end{array}$ & $\begin{array}{c}\text { Rio } \\
\text { Danube }\end{array}$ & $\begin{array}{c}\text { Rio Murray } \\
\text { Kiewa }\end{array}$ & Rio Aldan \\
\hline Área $\left(\mathrm{km}^{2}\right)$ & 450000 & 44548 & 510800 & 1005500 & 47495 & 1165 & 514000 \\
\hline Média $(\mu)$ & 1050 & 638 & 2808 & 14259 & 635 & 21 & 4223 \\
\hline Vazão específica (mm) & 74 & 452 & 173 & 447 & 421 & 568 & 259 \\
\hline Desvio padrão $(\sigma)$ & 401 & 190 & 768 & 1565 & 127 & 12 & 707 \\
\hline $\begin{array}{l}\begin{array}{c}\text { Coeficiente de Variação } \\
\text { (C.V) }\end{array} \\
\end{array}$ & 0.38 & 0.30 & 0.27 & 0.11 & 0.20 & 0.59 & 0.17 \\
\hline
\end{tabular}

Tabela 2 - Características hidrológicas dos países

Percebe-se que o país que apresentou o maior coeficiente de variação foi a Austrália, indicando que seus dados tiveram uma grande variabilidade em torno da média. 
Em contrapartida, a China apresentou o menor coeficiente de variação, o que representa um conjunto de dados mais homogêneo.

\subsection{Autocorrelação das vazões anuais}

Os correlogramas obtidos nas séries de vazões dos rios dos países em estudo pode ser observada das figuras 1 a 7 .

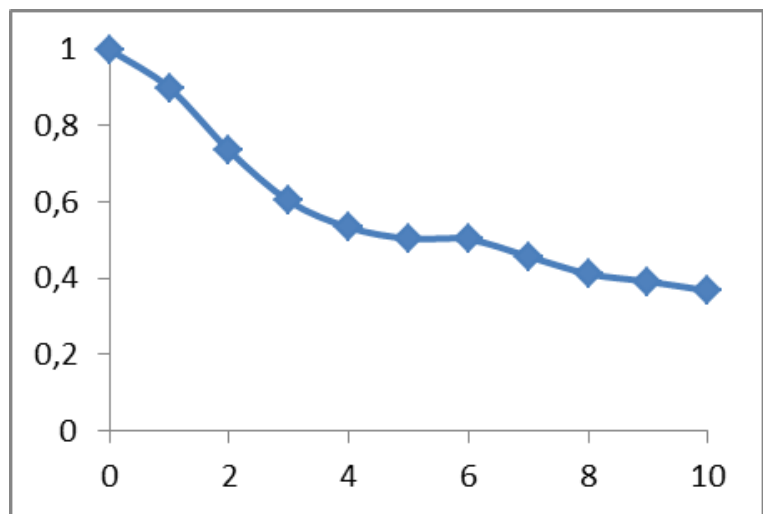

Figura 1 - Correlograma das vazões anuais do rio anuais do rio

Bahr el Jabel (África).

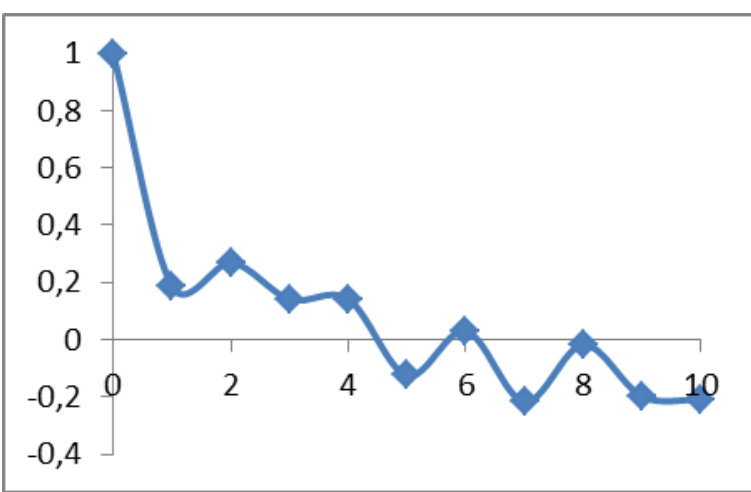

Figura 3 - Correlograma das vazões anuais do rio São Francisco (Brasil).

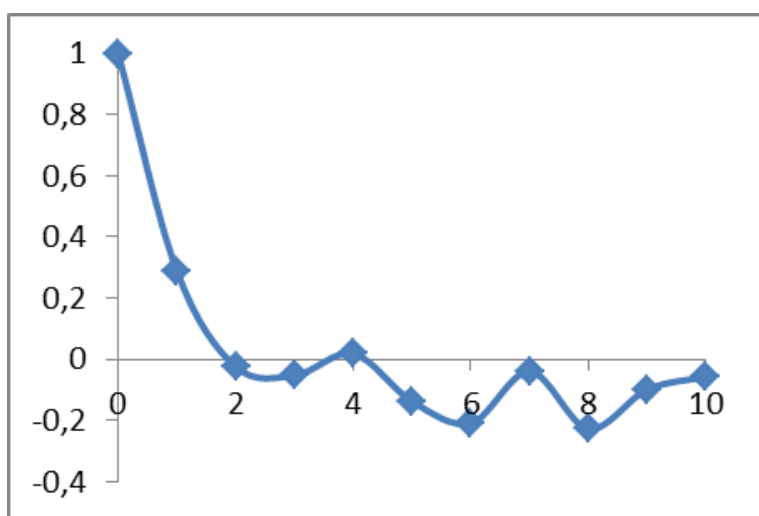

Figura 2 - Correlograma das vazões

Apalachicola (Estados Unidos).

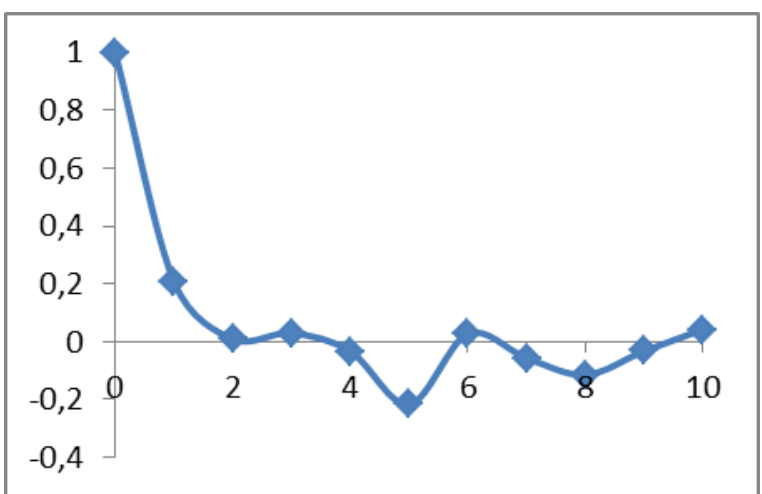

Figura 4 - Correlograma das vazões anuais do rio

Chanjiang (China). 


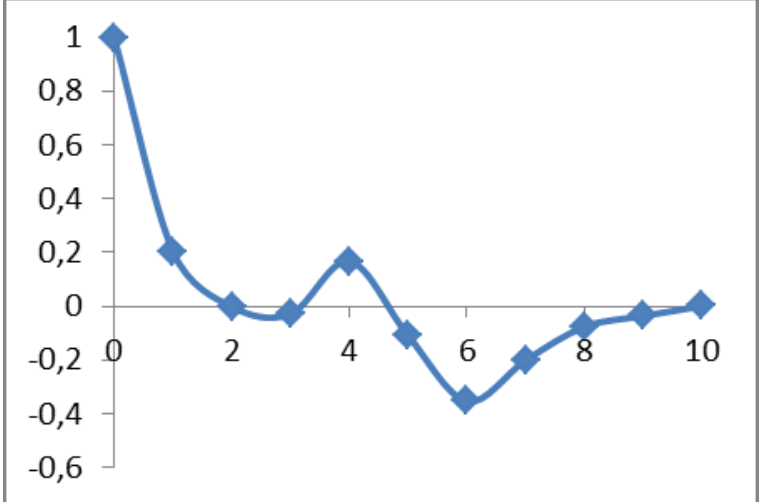

Figura 5 - Correlograma das vazões anuais do rio anuais do rio

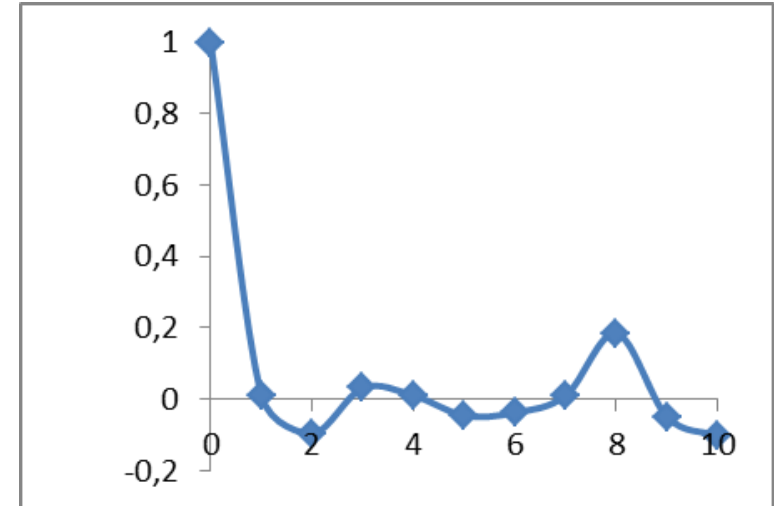

Figura 6 - Correlograma das vazões

Danube (Alemanha). Murray Kiewa (Austrália).

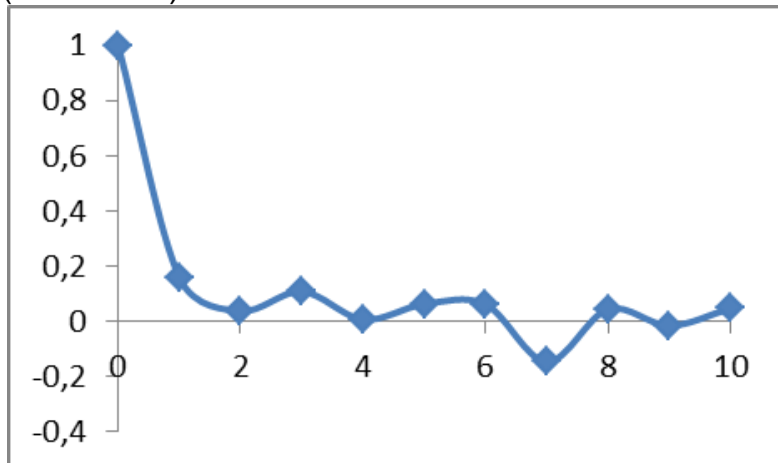

Figura 7 - Correlograma das vazões anuais do rio Aldan (Rússia).

\subsection{Sazonalidade intraanual}

$\mathrm{Na}$ Figura 8 pode-se observar que as vazões foram praticamente constantes durante todo o semestre, atingindo um valor máximo no mês de setembro em torno de $1200 \mathrm{~m}^{3} / \mathrm{s}$. Ao longo do ano o rio recebe vazões consideradas, revelando que há pouca variabilidade.
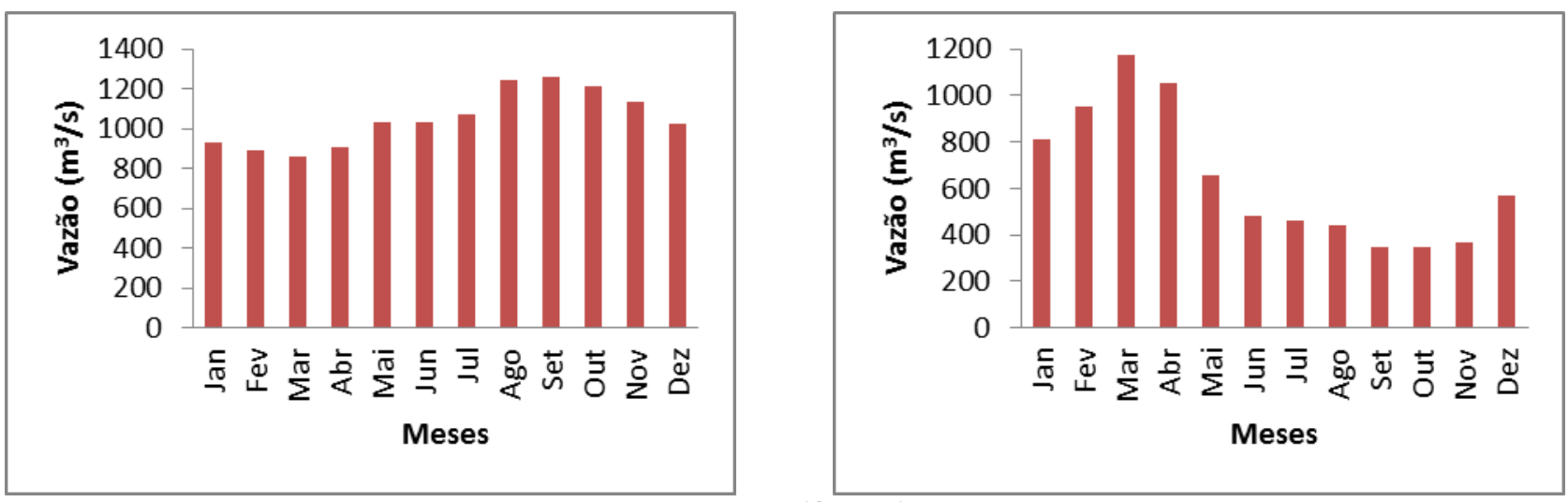

Figura 8 - Hidrograma de vazão no rio Bahr el Jabel (Sudão). Apalachicola (EUA). 
$\mathrm{Na}$ Figura 9 pode ser visto que no primeiro semestre as vazões foram superiores as ocorridas no segundo semestre, variando de 650 a $1190 \mathrm{~m}^{3} / \mathrm{s}$. Além disso, as vazões foram crescentes de janeiro a março e a partir daí passou a ser decrescente, voltando a crescer no mês de dezembro.

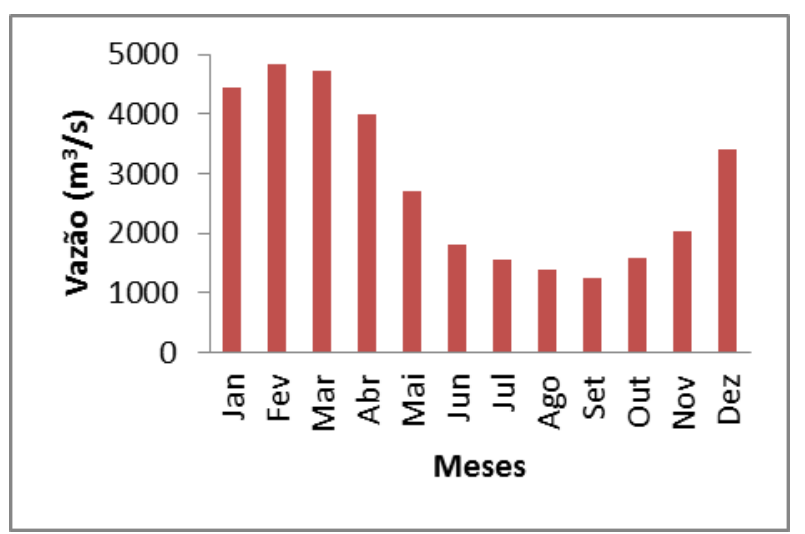

Figura 10 - Hidrograma de vazão no rio São Francisco (Brasil).

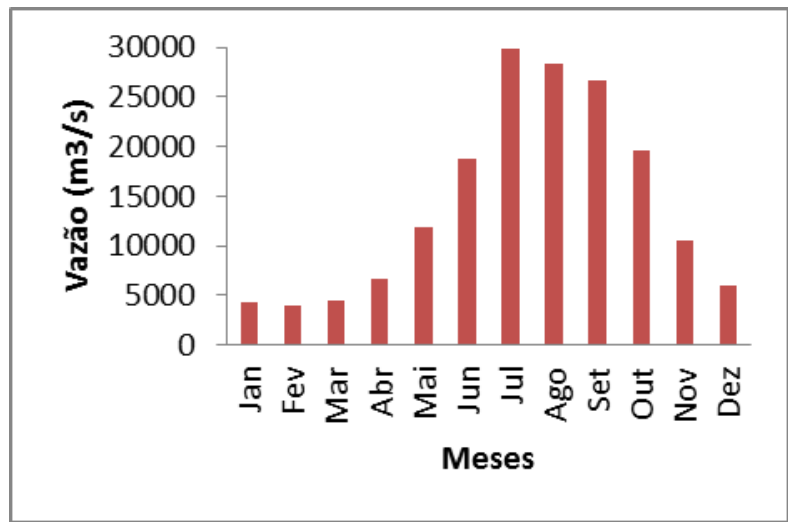

Figura 11 - Hidrograma de vazão no rio Chanjiang (China)

A Figura 10 mostra uma forte semelhança do comportamento do Rio São Francisco (Brasil) e o Rio Apalachicola (Estados Unidos). As vazões foram maiores no primeiro semestre, decrescendo a partir do mês de abril e voltando a crescer novamente em dezembro.

Ao contrário do que ocorre nos Estados Unidos e Brasil, percebe-se na Figura 11 que no Rio Chanjiang, na China, as vazões nos meses de janeiro, fevereiro e março foram praticamente constantes (em torno de $5000 \mathrm{~m}^{3} / \mathrm{s}$ ) e a partir de abril começou a crescer até atingir o máximo em julho (em torno de $30000 \mathrm{~m}^{3} / \mathrm{s}$ ). No segundo semestre, 
essas vazões começaram a decrescer até voltar para constante inicial no mês de dezembro.

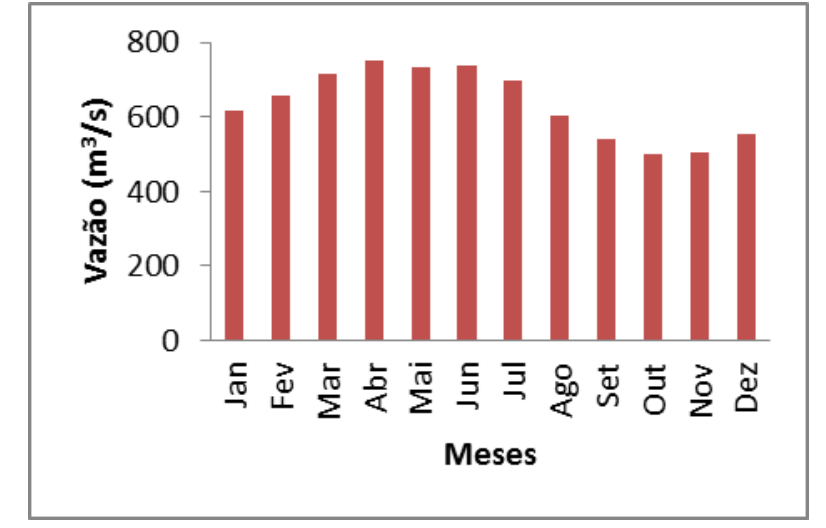

Figura 12 - Hidrograma de vazão no rio Danube (Alemanha).

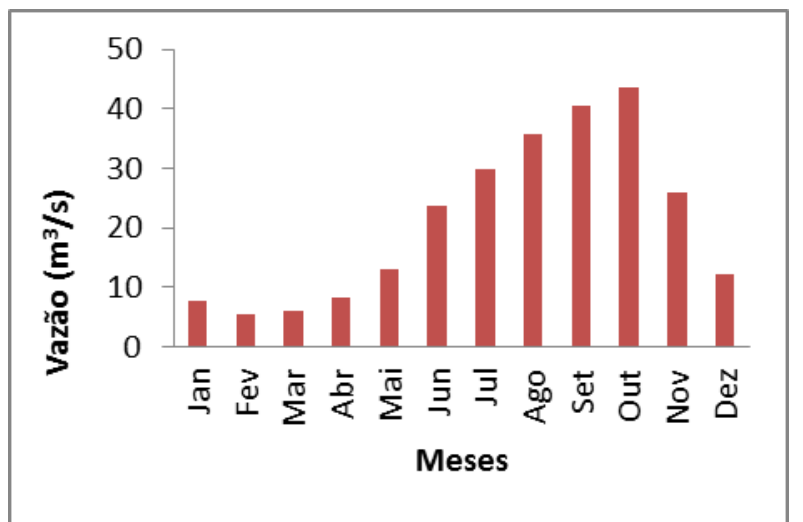

Figura 13 - Hidrograma de vazão no rio Murray Kiewa (Austrália).

Pela Figura 12 pode-se perceber que as vazões foram praticamente constantes sendo um pouco mais elevada no primeiro semestre. Observa-se que no mês de abril apresentou valor máximo (em torno de $750 \mathrm{~m}^{3} / \mathrm{s}$ ) e no mês de outubro apresentou o menor valor $\left(500 \mathrm{~m}^{3} / \mathrm{s}\right)$.

$\mathrm{Na}$ Figura 13 observa-se que as vazões crescem até atingir seu máximo (em torno de $45 \mathrm{~m}^{3} / \mathrm{s}$ ) no mês de outubro e depois volta a decrescer. As vazões são maiores no segundo semestre. 


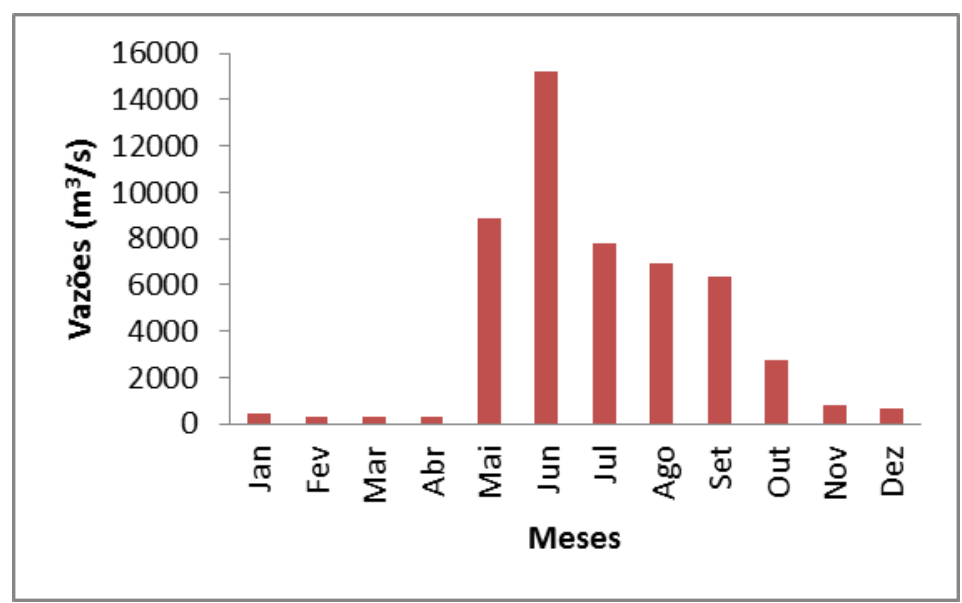

Figura 14 - Hidrograma de vazão no rio Aldan (Rússia).

$\mathrm{Na}$ Figura 14 verifica-se que no primeiro semestre as vazões foram inferiores as ocorridas no segundo semestre. Observa-se também que de janeiro a abril as vazões foram praticamente constantes (bem baixas), sendo crecente em maio e atingindo valor máximo em junho com aproximadamente $15000 \mathrm{~m}^{3} / \mathrm{s}$. Embora as vazões ocorridas no segundo semestre tenham sido decrescentes, as vazões foram superiores àquelas do primeiro.

\subsection{Vazões Máximas}

A Tabela 4 apresenta as máximas vazões obtidas com períodos de retorno $\left(T_{R}\right)$ de $10,50,100,1000$ e 10000 anos, assim como apresenta também as probabilidades e com z sendo uma variável aleatória com média zero e desvio padrão igual a um.

Tabela 4 - Valores das vazões máximas para diferentes períodos de retorno.

\begin{tabular}{|c|c|c|c|c|c|c|c|c|c|}
\hline \multirow[b]{2}{*}{$\begin{array}{c}T_{\mathrm{R}} \\
\text { (anos) }\end{array}$} & \multirow[b]{2}{*}{$\mathbf{Z}$} & \multirow[b]{2}{*}{ Probabilidade } & \multicolumn{7}{|c|}{ Vazão Máxima $\left(\mathrm{m}^{3} / \mathrm{s}\right)$} \\
\hline & & & $\begin{array}{l}\text { Rio Bahr } \\
\text { el Jabel } \\
\text { (Sudão) } \\
\end{array}$ & $\begin{array}{c}\text { Rio } \\
\text { Apalachicola } \\
\text { (EUA) }\end{array}$ & $\begin{array}{c}\text { Rio São } \\
\text { Francisco } \\
\text { (Brasil) } \\
\end{array}$ & $\begin{array}{c}\text { Rio } \\
\text { Chanjiang } \\
\text { (China) }\end{array}$ & $\begin{array}{c}\text { Rio } \\
\text { Danube } \\
\text { (Alemanha) }\end{array}$ & $\begin{array}{c}\text { Rio Murray } \\
\text { Kiewa } \\
\text { (Austrália) }\end{array}$ & $\begin{array}{c}\text { Rio } \\
\text { Aldan } \\
\text { (Rússia) }\end{array}$ \\
\hline 10 & 1.282 & 0.1 & 1994.4 & 2147.3 & 8877.0 & 40873.4 & 1387.7 & 96.8 & 20738.4 \\
\hline 50 & 2.054 & 0.02 & 2597.1 & 2926.6 & 11598.4 & 46334.8 & 1689.9 & 150.4 & 25133.5 \\
\hline 100 & 2.326 & 0.01 & 2850.3 & 3264.0 & 12744.4 & 48428.1 & 1811.3 & 175.7 & 26894.7 \\
\hline 1000 & 3.09 & 0.001 & 3701.6 & 4434.3 & 16605.4 & 54827.6 & 2201.3 & 271.7 & 32529.7 \\
\hline 10000 & 3.719 & 0.0001 & 4590.2 & 5706.7 & 20647.7 & 60726.3 & 2584.6 & 388.9 & 38044.8 \\
\hline
\end{tabular}

\subsection{Função densidade de probabilidade}


Com os dados dispostos na Tabela 3, relativo aos parâmetros (média e desvio padrão) que compõem as características hidrológicas dos rios, pode-se levantar a distribuição que melhor se ajusta as séries de dados de vazão dos países.

As distribuições utilizadas neste trabalho foram a Normal, Log-Normal e Gama. Todos os cálculos foram feitos no Excel.

O valor crítico do $\chi^{2}$ pode ser obtido na planilha do Excel pela fórmula: INV.QUI (probabilidade; grau de liberdade). Se o valor do $\chi^{2}$ obtido na equação for superior ao valor crítico do $\chi^{2}$ então rejeitamos a hipótese nula; caso contrário, aceitamos que a amostra pertence à distribuição.

Tabela 5 - Valores do $\chi^{2}$ para os dados de vazões dos países

\begin{tabular}{|c|c|c|c|c|c|c|c|}
\cline { 2 - 7 } \multicolumn{1}{c|}{} & $\begin{array}{c}\text { Rio Bahr el } \\
\text { Jabel } \\
\text { (Sudão) }\end{array}$ & $\begin{array}{c}\text { Rio } \\
\text { Apalachicola } \\
\text { (EUA) }\end{array}$ & $\begin{array}{c}\text { Rio São } \\
\text { Francisco } \\
\text { (Brasil) }\end{array}$ & $\begin{array}{c}\text { Rio } \\
\text { Chanjiang } \\
\text { (China) }\end{array}$ & $\begin{array}{c}\text { Rio } \\
\text { Danube } \\
\text { (Alemanha) }\end{array}$ & $\begin{array}{c}\text { Rio Murray Kiewa } \\
\text { (Austrália) }\end{array}$ & $\begin{array}{c}\text { Rio Aldan } \\
\text { (Rússia) }\end{array}$ \\
\hline $\begin{array}{c}\text { Distribuição } \\
\text { Normal }\end{array}$ & 33.5 & 0.7 & 4.5 & 4.6 & 3.2 & 23.8 \\
\hline $\begin{array}{c}\text { Distribuição Log- } \\
\text { Normal }\end{array}$ & 27.9 & 4.2 & 1.3 & 5.4 & 9.4 & 6.4 \\
\hline $\begin{array}{c}\text { Distribuição } \\
\text { Gama }\end{array}$ & 26.7 & 4.2 & 1.5 & 5.4 & 8.6 & 9.6 \\
\hline
\end{tabular}

\section{CONCLUSÕES}

Após a análise de todos os resultados pode-se concluir que das séries estudadas a que apresentou um menor coeficiente de variação foi o rio Chanjiang (China), com um valor de 0.11 , mostrando que seus conjuntos de dados são os mais homogêneos. Em contrapartida, o rio Murray Kiewa (Austrália) apresentou o maior coeficiente (0.59).

Foi observado que os dados de vazão do rio Bahrl el Jabel (Sudão) não puderam ser ajustados em nenhuma das três distribuições.

As distribuições gama e log-normal ajustaram igualmente os dados de vazão dos rios Apalachicola (Estados Unidos) e Chanjiang (China). A distribuição normal foi a que melhor ajustou os dados do rio São Francisco (Brasil). A distribuição gama foi a que melhor ajustou os dados de vazão do rio Murray Kiewa (Austrália). A distribuição lognormal foi a que melhor ajustou os dados dos rios Danube (Alemanha) e Okhotskiy Perevoz (Rússia).

O rio Chanjiang (China) apresenta os maiores valores de vazões máximas para os períodos de retorno de 10, 50, 100, 1000 e 10000 anos. 


\section{AGRADECIMENTOS}

Nossos agradecimentos a Capes e ao CNPq e, pelo suporte financeiro através de bolsa de estudo que permitem que esta pesquisa se desenvolva.

\section{REFERÊNCIAS BIBLIOGRÁFICAS}

CAMPOS, J. N. B. Lições em modelos e simulação hidrológica. Editora ASTEF. Fortaleza, 2009.

UNESCO, 1977. Atlas of World Water Balance. UNESCO.

UNESCO, 1978. World water balance and water resources of the earth. Studies and Reports in Hydrology 25.

McMahon, T.A., Vogel, R.M., Peel, M.C., Pegram, G.G.S., 2007c. Global streamflows Part 1: Characteristics of annual streamflows. Journal of Hydrology 347 (3-4), 243-259.

McMahon, T.A., Vogel, R.M., Pegram, G.G.S., Peel, M.C., Etkin, D., 2007d. Global streamflows - Part 2: Reservoir storage - yield performance. Journal of Hydrology 347 (34), 260-271.

McMahon, T.A., Peel, M.C., Vogel, R.M., Pegram, G.G.S., 2007b. Global streamflows Part 3: Country and climate zone characteristics based on global historical streamflow data. Journal of Hydrology 347 (3-4), 272-291. 